No campo da pesquisa sobre a psicanálise e infância, o texto apresenta perguntas $e$ reflexōes surgidas da análise da experiência, já passada, da autora como diretora da Secretaria da Infância órgão público municipal de ajuda e proteção da infância (Mar del Plata, Argentina).

Apresenta-se a história pública de um menino de rua, recolocando interrogantes sobre os efeitos subjetivos quando o discurso sobre a menoridade tenta determinar a direção e sentido da vida.

Psicanálise; infância; minoridade

\section{PUBLIC HISTORY.}

PRIVATE SECRET

In the context of the studies on psychoanalysis and infancy, in this article are exposed inquiries and reflections that arise from the analysis of the author's practice and experience as a former chief of the Direction, a municipal public service of the city administration (Mar del Plata, Argentina). This case, the public history about a child who lives in the streets, renovates questions about the consequences of the constitution of the subject, when the minority discourse tries to sign the direction of the life.

Psychoanalysis; infancy; minority

\section{HISTÓRIA PÚBLICA. SEGREDO PRIVADO}

\author{
Mercedes S. Minnicelli
}

Tradução: Daniela Teperman

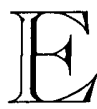
1999, p. 54-63) - apresentei a seguinte reflexão: "Não é possível dirigir a infância", mas "são as marcas da infância que determinam a direção da vida dos sujeitos".

As vicissitudes dessa história apresentam particularidades que não são, precisamente, as que podemos considerar propícias para nenhuma vida humana. No entanto, não se trata do anedótico do caso, mas de expor a constatação de que aquilo que se apresenta como destino inexorável está marcado pela negligência de um sistema de "proteção à infância" levada à sua mais nítida expressão.

A história de Roman incorpora-se em minhas reflexões promovendo diversas vias de análise e investigação. A mais significativa e contundente é comprovar que sua loucura não é mais que produto e expressão da loucura de um sistema, ao qual, apesar de tudo, ele apela.

A criança dessa história evidencia a tenaz luta de uma subjetividade por não ser executada.

Mercedes S. Minnicelli é psicanalista, psicóloga, ex-diretora da Infância, subsecretária do Menor, Familia, Terceira Idade e Deficientes, secretária de Qualidade de Vida na Municipalidade de General Pueyrredón, na Argentina. 
Costurar um texto, partindo de fiapos espalhados, levou-nos a ressaltar a análise do contexto discursivo no qual essa vida transita, ficando aprisionada em um labirinto cuja única saída resulta paradoxal: escapar para ficar cada vez mais preso. Na tentativa de desfazer-se da filiação a um infanticídio, a criança defende em "segredo" o "público" de seu "passado", que não o é, uma vez que se atualiza no presente, mostrando-se de novo sob a forma do sinistro (Freud, 1919).

Este artigo faz, então, o caminho inverso ao da criação de uma ficção. A pergunta que partilhamos com o leitor é sobre a possibilidade, para um frágil psiquismo infantil, de driblar as provas de um realismo superador da ficção, que precipita insistentemente ao sinistro no real deixando uma margem sumamente estreita para a veiculação de uma operatória simbólica.

Seu título "história pública" refere-se ao paradigmático e representativo deste caso, tendo em vista as inúmeras crianças que hoje perambulam pelas ruas. História que se torna pública, neste caso, a partir de um infanticídio no e do qual, posteriormente, participam diversos "atores públicos" (juízes de menores, secretários, polícia, profissionais, preceptores, funcionários, docentes, etc.) encarnando "personagens" que adquirem vida seguindo um roteiro próprio a uma sátira ou novela. Roteiro de uma história cujo argumento, por não ser uma ficção nem dar lugar à mesma, atrevemos-nos a qualificar como obsceno.

“(...) Os teatros captam todos os sentidos em suas representações excitantes e inclusive em artes plásticas orientam-se com preferência ao feio, repugnante excitante, sem espantar-se a nossos olhos com um repugnante realismo, o mais horrível que a realidade pode oferecer-nos” (Freud, 1908).

Convidamos o leitor a participar dessa história, que não é de teatro.

\section{ATO I}

Nosso primeiro contato com a história de Roman ocorre por meio do relato de terceiros à "direção da infância". Assim o apresentam: uma criança "de rua" ingressa por decisão judicial em um abrigo de admissão ${ }^{1}$ no verão de 1998. Tem 12 anos. As intervenções judiciais começaram há sete anos. Sua permanência no "abrigo" é breve. Foge (ausenta-se sem consentimento) ${ }^{2}$ uma e outra vez. Durante estas ausências perambula pelas ruas, mas não por qualquer lugar. Tem "paradas”. Uma delas é o McDonald's. Passa al- 


\section{Artigo}

gumas horas "cuidando de carros" e com o dinheiro que junta compra o "Mclanche feliz", nome de uma apresentação dos produtos dessa empresa para atrair crianças felizes...

As tradicionais instituições do Estado destinadas à atenção de "menores" concentram sua atenção na "satisfação de necessidades"; um espaço físico onde receber comida e um lugar onde dormir, preceptores encarregados da atenção às crianças. $O$ "menor" deve pagar com a adaptação à arbitrariedade de normas estabelecidas pela tradição em menoridade. Seu dever é agradecer o que recebe e ficar no lugar que lhe determinam.

Roman recusa essa "ajuda". Foge. No entanto, quando cai a noite, dirige-se a lugares onde a polícia ou o pessoal de prevenção ${ }^{3}$ pode encontrá-lo. Podemos dizer que se oferece para que o encontrem. Em cada uma dessas ocasiões é reintegrado ao abrigo de admissão.

Seus atos são interpretados tal como o assinalara Winnicott: "A opinião corrente é que, ao encontrar-se 'livre', procede a desfrutar dessa situação. Isso está muito longe da verdade. Ao ver destruído o marco de sua vida, já não se sente livre. Torna-se ansioso, e, se tem esperanças, começa a buscar um marco fora do abrigo. (...) busca uma estabilidade externa sem a qual pode perder a razão” (Winnicott, 1946, p. 139).

Esse movimento é repetitivo: instituição (entrada) / recusa fuga (saída) / ruas / busca - encontro... O jogo do "gato e o rato".

Integrantes da equipe técnica da casa de admissão observam que leva sempre consigo uma sacolinha de plástico com brinquedos. Quando vai embora, sempre deixa algum na casa de admissão.

Começa a sobrar-lhe dinheiro do que arrecada "cuidando de carros". Pede ao diretor que o guarde, porque quer juntar para comprar um relógio. Diz temer que os outros meninos o roubem. A convivência torna-se realmente difícil. Roman não respeita nenhuma norma que o contradiga. Sente-se preso, se descontrola e entra em crise, caindo no choro quando os preceptores tentam limitar suas fugas. A proposta foi possibilitar (outorgando a permissão) que Roman saisse e regressasse em uma hora determinada. Para cumpri-la, primeiro tinha de aprender as horas. Deixava na casa de admissão algo que the pertencia e voltaria para buscar: suas "economias". Ele assinava em um papel quando entregava o dinheiro e voltava a assinar se o pedia-o de volta. "Entrava e saía" dinheiro de sua conta $(\$ 1 ; \$ 1,50 ; \$ 2)$, criando-se um incipiente espaço intermediário que possibilitava um outro cenário. Diz não saber desenhar nem escrever. 
Roman permanentemente se diferencia dos "outros" meninos da rua. Ele diz "eu não roubo nem fumo, não sou como eles", mas sua busca por estabelecer diferenças fracassa.

Diversos agentes acompanharam o incansável e esgotador movimento da criança e intervieram em diferentes circunstâncias, tanto durante as breves estadas institucionais, como na rua, em momentos verdadeiramente difíceis e críticos.

A sucessão de acontecimentos dispersos e difusos, paulatinamente começou a concentrar-se, mediante a escuta e tentativas de esclarecimento da demanda formulada pelos profissionais, diretores, operadores encarregados diretamente do tratamento da criança dirigida "à direção". Vale esclarecer que somente em algumas ocasiões, a supervisão do caso ocorreu em reuniões e/ou entrevistas programadas. A emergência da demanda se produzia a qualquer hora, de dia, de noite... mediante consultas telefônicas do pessoal (preceptores e operadores), ou dos próprios profissionais a partir de conflitos que gerara a estada e/ou fuga da criança em/de algum dos abrigos nos quais se encontrava, ou também por encontrá-la dormindo na rua.

Em todos esses casos, a única coisa que parecia possível era tentar reconstruir a sucessão de acontecimentos, buscando certa lógica na dispersão, no que se apresentava desagregado. A referida reconstrução possibilitou uma nova via de análise: aquela que nos permitiu interrogarnos sobre a repetição dos atos que foram sucedendo-se entre cada entrada e saída. 
A "chave", talvez, estava presente nos intervalos. Entrar e sair, jogo de presença e ausência, no qual o presente ou ausente era "ele mesmo" apenas aparentemente; havia um resto, aquilo que deixava "presente" em cada uma de suas "ausências": vidros quebrados, brinquedos, roupa suja, brigas e mais tarde jogos sexuais... $\mathrm{O}$ que se fazia presente para ele obrigando-o a fugir de maneira compulsiva e fracassada?

Uma idéia ganhava força, Roman "enlouquecia" a todos, e o confronto imaginário crescia entre aqueles que de um modo ou de outro intervinham no "caso". O estouro institucional parecia eminente.

\section{ATO}

O juiz determina a transferên$\mathrm{cia}^{4}$ de Roman a La Plata para um abrigo de internação de regime fechado. Esta é efetivada e depois de poucos dias Roman está novamente de volta a Mar del Plata, perambulando pelas ruas. Fugiu antes de chegar ao "movimento e localização" na cidade de La Plata ${ }^{5}$.

O mundo adulto responde e se impōe. A intervenção judicial aponta na direção de "privá-lo de liberdade", prendendo-o em uma delegacia ou em um "instituto de regime fechado". Longe de aceitar essa imposição, e sabendo que ali não encontrará o amparo que lhe faz falta, foge, retornando a seus lugares conhecidos, onde - quem sabe? - alguém irá procurá-lo.

Prendê-lo é algo "justificado". O pai de Roman matou a filha (12 anos), sua irmã, depois de violentá-la quando ele tinha 5 anos $^{6}$. Acredita-se que ele tenha presenciado a cena. Esse homem está condenado e preso. A mãe não cuida nem de Roman, nem de seus outros oito filhos.

Os efeitos da violência simbólica (Bourdieu) exercida pelo discurso de menoridade, detentor do saber sobre os fatos "reais" da vida das crianças, que elimina qualquer tentativa de fazer outra coisa com esta "realidade".

E a criança, como se fosse um adulto em miniatura, tem de se virar como pode para burlar as decisões que juizes, instituições, funcionários, etc., detentores de um Saber Supremo, impõem-lhe à força. Medidas de coerção e prisão, que menosprezam o fato de que não é delito ser portador de um horroroso padecer, produto de um ato do qual ele é (foi) testemunha involuntária, e não autor.

No entanto, Roman insiste e resiste, até fazer que se escute, leia, interprete, responda a seu grito de espanto; brigando para que seu chamado se transforme em demanda de Outro e outorgue suporte ao desamparo subjetivo em que se precipita.

Das marcas de sua história familiar, truculenta por certo, o menino fracassadamente tenta desfazer-se, fragmentando seu mundo em pedaços, que espalha e deixa em cada um dos lugares de onde "entra" e "sai".

A fuga de Roman das tentativas judiciais de prendê-lo levou-nos a propor uma "intervenção alternativa", fundamentada na legalidade da Convenção Internacional dos Direitos da Criança. Insistir na possibilidade de 
operar acompanhando, desde a própria casa de admissão, esse movimento rítmico de sair e regressar ${ }^{7}$, criando entre a rua e a casa de admissão, um espaço intermediário. Com poucas esperanças, o juiz concede-nos o aval verbal para realizar esta tentativa.

"Nessa seriedade, da qual está ausente a fantasia, a criança por sua vez encontra-se imersa e como que presa em uma armadilha. E é então no real que põe em jogo seu medo e sua violência, a falta de outra cena, de um espaço de brincar no qual projetar seus fantasmas e criar, 'para rir', monstros, gigantes ou anões" (Mannoni, 1976, p. 13).

Por um tempo, Roman, ainda que oficialmente esteja "internado" na casa de admissão, aceita a proposta de freqüentar outro lugar, A Parada ${ }^{8}$, onde encontra aqueles que ele identifica como "amigos", uma equipe de trabalho ambulatório formada por operadores, psicólogos e uma assistente social que o conheciam do tempo em que estava na rua.

Não tenta esconder-se ou escapar quando está com eles. Permanece ali durante o dia apesar de o lugar estar preparado para atender crianças, e não para albergá-las. Paulatinamente vão the oferecendo papel, canetas e uma caixa com brinquedos. Começa a desenhar, pintar e brincar. Insiste em que seus desenhos estejam à vista, pendurados em uma parede. Roman começa a mostrar interessantes avanços artísticos e solicita materiais que antes recusava. Cria-se um novo cenário a fim de tentar oferecer um lugar àquilo que o enlouquecia, e os momentos da fuga, além de atos críticos, passam a ter palavra. Participa de atividades sociais e culturais (obras de marionetes, plástica, etc.), e melhora a relação com outras crianças em espaços abertos. No entanto, foge da casa de admissão acusando os garotos e preceptores de "violines" 9 , disparado pela cena de um preceptor conversando amigavelmente com outro menino em um dos dormitórios. Por um tempo não retorna a essa casa, mas vai todas as manhãs ao A Parada.

A partir de uma briga na rua, na qual tomou uma surra brutal que levou à sua hospitalização, o juiz determina que seja "internado", novamente, na casa de admissão ${ }^{10}$, de onde vai embora poucas horas depois de ter ingressado e após protagonizar um episódio de confronto violento com os outros adolescentes alojados na mesma.

Mesmo tendo escapado da casa de admissão, mantém-se no circuito institucional, vai à sede da Secretaria de Qualidade de Vida Municipal, onde decidimos permitir que pernoitasse transitoriamente. Nesse local funcionam diversas oficinas públicas, portanto, ele teria que se levantar cedo pela manhā. Ao despertar, arrumava prolixamente seu colchão, suas mantas e sua roupa. 
Apresenta-se uma oportunidade para propor-lhe uma entrevista, uma conversa. Decido perguntar-lhe o que pensa sobre o que está ocorrendo, sobre o que o leva a não permanecer em nenhum lugar, menciono a surra recebida e a cena de violência experimentada na casa de admissão, ao que responde: "Vocês não têm um lugar para mim, não entendem?!, Não é pra mim nem a casa de admissão nem o abrigo $X$ nem o $K$ ". "Sim, é verdade o que você diz", respondo-lhe, "mas você é muito pequeno para acreditar que pode se virar sozinho, ninguém se vira sozinho na vida e, se esses lugares não são pra você, como você diz, teremos de encontrar outro, um lugar onde você possa sentir-se bem... certamente deve existir algum lugar para você, sempre e quando possa aceitá-lo”.

Suas palavras, desafiantes e verdadeiras, podemos lê-las quase literalmente, dizem: "O que vocês me oferecem não me faz falta". Ressoam nas fibras íntimas do político (pondo em questão a eficácia do Estado para atender à infância em situação de abandono) e da psicanálise: não se trata do objeto, mas da falta de objeto, aquilo que faz de um ser de necessidade um sujeito desejante. Uma verdade aflorava. "A relação central de objeto, a que é dinamicamente criadora, é a da falta” (Lacan, 1994, p. 54).

Entretanto, tratava-se de não cair na armadilha de dar crédito a seu desafio, mas de escutar suas palavras e começar a operar com elas. O que lhe faz falta? Ou, para ser mais precisos, o que não the faz falta? Momento de pesquisa dos significantes que as ações e ditos da criança punham em jogo.

Algo da transferência se instalava a cada novo contato, deixando "algo dito" entre esse entrar e sair; dito a partir do qual tornava-se possível para nós uma outra função: a de fazer dizer.

\section{ATO III}

Roman encontra abrigo na casa de uma mulher conhecida por deixar entrar crianças da rua para comer, tomar banho e dormir. Esta casa é algo como um "albergue de transgressores" (sic). Permanece um tempo nessa casa aceitando condições mínimas de estabilidade, que the permitem dizer: "Tenho de passar por todos os lugares para buscar minhas coisas, tenho-as espalhadas, em $\mathrm{X}$ tenho meus brinquedos, em $\mathrm{Y}$ tenho minha roupa que deixei para lavar, em $\mathrm{J}$ tenho os lápis que fulano me deu, em $\mathrm{K}$ tenho as figurinhas que sicrano me deu para levá-las na casa da tia..." Momento reparador o do reencontro de e com suas "coisas" espalhadas. 
Roman começa a freqüentar uma casa da criança, instituição de regime diurno, a fim de participar de atividades sociais e educativas. Este é um momento que surpreende. Expressa o desejo de freqüentar esta instituição e de aprender a ler, escrever e fazer cálculos em um caderno que leva e traz. Deixa de perambular e se vira bem entre os colegas. Deseja higienizar-se diariamente e estar "lindo". Também vai ao A Parada.

\section{ATO IV}

Recebe uma carta, na véspera do Dia das Mães - provavelmente um de seus irmãos entregou-a -, na qual sua mãe lhe escreve: "Filho, amo-o muito. Lamento que você não queira viver comigo e que prefira outros". Roman escapa da casa da sra. Z., deixando a carta sobre a mesa. (Não sabia ler?) Leva uma bicicleta, e todos supomos que retorna à sua casa, o que, constataríamos depois, não ocorreu. Deixa de freqüentar a casa da criança e volta a vaguear pelas ruas.

(A mãe, estaria tentando "juntar" seus "filhos" espalhados por aí?)

\section{ATO $V$}

A polícia encontra-o dormindo na praça em frente à Municipalidade e leva-o à delegacia. Este momento coincide com mudanças no pessoal policial, e os novos agentes não o conheciam. Informam ao juiz, averigúam seus "antecedentes" e registram a "entrada" com a palavra que consta na capa do processo judicial do Tribunal de Menores - "homicídio" - como sua "causa". Sua "entrada" é registrada como "homicídio"11 (sic), passando a ser considerado imediatamente um menor perigoso. Do Tribunal entram em contato com a Direção da Infância para avisar que estava na delegacia, ordenando sua internação na casa de admissão até sua transferência para La Plata.

A assistente social da equipe ambulatório ("amigo") vai visitálo na delegacia. Está desgrenhado, cansado e muito irritado. Durante dias vagueou sem rumo. Em sua irritação diz: "Estes policiais não acreditam em mim, que não sou homicida, eu não matei ninguém". A causa de homicídio é do pai. Somente foi testemunha dessa aberração quando tinha 5 anos. No entanto esta é sua insíg- 


\section{Artigo}

nia, sua vergonha e sua condenação. Tal como ele nos dirá posteriormente, seu segredo.

Mais uma vez, aquilo que se oferece como amparo material, como contexto, exterioridade à qual a criança apela, abrigando talvez alguma esperança de que sua própria "realidade" enquanto Real possa inscrever-se simbolicamente, apenas precipita-o a um maior desamparo, o da alienação que o identifica ao significante "homicida", inscrevendo-o na linhagem dos atos do pai, e não de seu nome.

Esse dito se ressignificava aprèscoup, demonstrando a dispersão de restos de seu próprio mundo, marcado por experiências miseráveis para qualquer ser humano, determinadas para Roman pelo horror da imagem da cena protagonizada por seu pai e sua irmã, de estupro e morte, escapando do circuito de legitimação (Bourdieu) que o reconhece, identificando-o aos significantes estuprador e homicida.

Foi deixando os rastros de seu padecer em cada uma das instituições pelas quais foi transitando, sob diversas formas - cuja repetição (Nasio, 1994, p. 3) forneceu-nos alguma pista orientadora. Paulatinamente foi criando-se uma hiância, um espaço intermediário, a folha de papel, onde deixar seus desenhos - tentativas de inscrição simbólica - e mais tarde suas palavras, que expressaram o padecer da criança alienada sem jogo de separação à identificação à causa de seu pai, homicídio. Alienação ativada e reativada nas sucessivas intervenções oficiais.

As verdadeiras e ocultas mesquinharias do discurso de menori- 
dade tornaram-se patéticas. A causa de seu pai foi o que deu motivo ao Estado para intervir. Como não escapar, se o que a criança buscava era proteger-se do horror do ato de infanticídio, de incesto e morte.

Sua inscrição no universo lingüístico da legalidade social, seu "prontuário", carta de apresentação social da criança sob tutela judicial, marca o nome pelo qual é nomeado: "homicida". E os sucessivos agentes que foram intervindo em sua curta vida, o identificaram ao nome, confundindo-o com a causa judicial de seu pai.

"Ninguém acredita que eu não sou assassino, eu não matei ninguém." Como não tentar fugir de todos e de cada um dos possíveis representantes (paternos) do assassino? Sua desconfiança é legítima, não se dá crédito a suas palavras.

Depois dessa passagem pela delegacia, o juiz volta a determinar sua internação na casa de admissão, onde outros adolescentes ali também residentes transitórios encontram-no escondido realizando jogos sexuais com um menino pequeno, de aproximadamente 5 anos - a mesma idade que ele tinha quando presenciou o estupro e homicídio de sua irmã -, avisando imediatamente aos preceptores. Este episódio promoveu sua expulsão, sem mediação de nenhuma palavra, possibilitando-lhe escapar da tentativa de linchamento por parte dos adolescentes alojados na casa que o encontraram com o menininho.

A carta da mãe, a repetição de sucessivas entradas e saídas, a nomea- ção de homicida, rebelar-se contra essa associação, o jogo sexual que tinha protagonizado...

Perguntamo-nos: a reação dos outros garotos dizendo "isso não se admite" operaria como ato veiculador da interdição da Lei?

\section{ATO V}

Novamente a polícia o encontra, mas desta vez levam-no à sede de Qualidade de Vida. O juiz determina uma nova transferência à delegacia para ser levado a La Plata. A polícia nega-se a transferi-lo contra sua vontade.

Aceito a responsabilidade de dar a notícia a Roman. Considero oportuno trabalhar com ele a decisão judicial.

Durante a entrevista, brinca com objetos da escrivaninha e realiza desenhos em diversas folhas, que me entrega como "presente". Está inquieto, sai da sala e entra em outra of - $^{-}$ cina, onde encontra uma sacola com brinquedos e um pacote de figurinhas. Vem me procurar para exigir que lhe dê de presente as figurinhas. Diante de sua surpresa, digo-lhe que não. Insiste. Proponho então que as joguemos. Se ele ganhar, pode leválas, se perder, elas ficam comigo. Aceita imediatamente e expressa: "Bom, vamos jogar a 'tapadita".

"Nesse sentido, devemos aceitar que o sintoma dominante na infância atual é a marginalidade. $O$ principal desafio da sociedade atual tem sido descobrir e controlar o momento 
preciso de passagem da vulnerabilidade social à marginalidade definitiva de uma criança" (Volnovich, 1999, p. 34).

Foge (?) da delegacia antes de efetivar-se a transferência determinada pelo juiz. Por vários dias se desconhece seu paradeiro. Escapa e já não escolhe lugares conhecidos. Leva uma surra na rua, que renova a intervenção policial, a assistência no hospital e a ordem de transferência do juiz. Levam-no à sede da Secretaria, onde, logo após chegar, irrompe em uma crise de choro e chuta quem se aproxima atraindo a atenção do público presente. Tenta por todos os meios tirar o gesso que tinham colocado em seu braço.

Em todas e em cada uma das oficinas havia rastros de sua passagem pelo lugar. Pedaços de gesso, desenhos, brinquedos jogados, figurinhas espalhadas pelo chão, pelas salas, pelo corredor.

No entanto, dessa vez a dispersão estava concentrada sob um mesmo teto e já não em diversos estabelecimentos institucionais, como antes relatamos. Algo estava acontecendo, ainda que não pudéssemos nos dar conta do que se tratava. Pernoitou na sede da secretaria. No dia seguinte, por volta do meio-dia pede para falar comigo. Faço-o esperar sem ocultar-lhe que desaprovava a confusão que provocara no dia anterior.

Roman senta-se e, ante a pergunta sobre o que queria falar, responde (enquanto brinca com uns aviōezinhos de plástico) "meu pai está no inferno”. Em aparente desentendimento, pergunto:

- Onde fica?
- Você não sabe onde fica?

- Não - insisto. (Enrosca-se na cadeira, levanta-se, procura os aviõezinhos que antes tinha atirado pelo ar.)

Volto a perguntar:

- Onde fica o inferno? (Finge que não escuta.)

Insisto, até que responde exaltado:

- Na cadeia, é isso, esse é o inferno, ou você não sabia!!!???

- Não, não sabia. Achei que a cadeia era a cadeia. Por que ele está na cadeia? (Começo a brincar com os mesmos aviõezinhos que estavam sobre a mesa, jogo para ele, que os devolve.)

- Isso eu não vou the dizer, porque é um segredo. (Fico surpresa com esta resposta, penso que está me oferecendo algo chave.)

- Mas você pediu para falar comigo, queria contar seu segredo?

- Talvez... Quê!! Você não sabe por que o levaram para a cadeia, bah! Ao inferno?

- Você nunca me contou. O que eu tenho de saber?

- Você não sabe porque é um segredo. (Reitera, e ri zombeteiro.)

- É, claro! (Respondo no mesmo tom.) Se é um segredo e você não me contou, como vou saber?!!! É seu segredo?

- Sim.

- Você quer me contar?

- Bom!! Mas você não pode contar pra ninguém, eh!! (Expressa com tom ameaçante e o dedo instigador.) Você tem que guardar o segredo.

- O que você nunca contou a ninguém? 
- Meu pai violentou e depois matou a minha irmãzinha, por isso está na cadeia...

Continuando o relato, com impactante comoção (sua e minha), da cena na qual escutou o barulho do disparo que matou sua irmã, como saiu correndo, ao pressentir o que ocorrera, presenciando a cena uma vez produzido o crime.

- Este é o meu segredo - acrescenta -, não o contei nunca a ninguém pelo que poderiam pensar. Isso que meu pai fez não se faz, entende?! É um idiota!!!!!

- Assim é, o que seu pai fez não se faz, e ele está na cadeia por isso. Mas você não é o seu pai. Você me deu seu segredo. Agora não é tão pesado para você sozinho. Você está muito bravo com ele?

- Você não sabe que linda que era minha irmã!!! (Começam as lembranças sobre brincadeiras com sua irmã, e descreve o lugar e o modo do enterro.) Minha mãe não sabe que a amo. Ela acha que não a amo. Me bate!! Minha casa é um barracão.

- Você quer contar-me como é? (Seu relato se detém nos cômodos, sua cama, seus brinquedos, seu quarto.)

É seu barracão, você acha que a praça é melhor para dormir?

- Minha mãe me bate, mas os meninos na rua também me batem.

- Tanto que você teve de ficar internado no hospital e agora está com o braço machucado.

- Quero ver a minha mãe, quero dizer que a amo, nunca lhe disse que a amo porque me bate, você me leva na minha casa para ver a minha mãe?

- Não sei se posso levá-lo. 

rem?

- Então, você diz para me leva-

A pergunta que Françoise Dolto formula em seu livro La dificultad de vivir ecoa em nós:

"Quais são, portanto, as condições necessárias e suficientes, no ambiente de uma criança, para que os conflitos inerentes ao desenvolvimento de cada ser humano possam resolver-se para aquela de forma saudável, ou seja, criadora; para que o momento decisivo do Édipo, e sua resolução na recomposição dos afetos, das identificações e os desejos incestuosos, abra passagem para uma pessoa atuante e responsável; para que a angústia de castração ligada ao complexo de Édipo desemboque no abandono das fantasias arcaicas ou perversas, intrafamiliares, e conduza o sujeito à sua expressão na vida social e na vida cultural simbólica, aceitando suas leis?" (Dolto, 1981, p. 20).

\section{REFERENCIAS BIBLIOGRÁFICAS}

Bourdieu, P. (1999). Meditaciones pascaliahas. Anagrama.

Dolto, F. (1981). Lal dificultad de vivir. Vol. II. Gedisa, 1986.

Freud, S. (1908). La moral sexual cultural y la nerviosidad moderna. In Obras completas. Madri, Biblioteca Nueva, 1972.

(1919). Lo ominoso. Buenos Aires: Amorrortu, 1995.

Lacan, J. (1994). Seminario 4. Lat relación de objeto (5/12/1956). Paidós.

Mannoni, M. (1976). Un lugar para vivir. Barcelona: Grijalbo, 1982.

(1993). Amor, odio, separación. Reencontrarse con la lengua perdida de la infancia. Buenos Aires: Nueva Visión, 1994.
Minnicelli, M. S. (1999). A novela social sobre a infância desamparada. Estilos da Clinica: Revista sobre a Infância com Problemas, 6 (IV), 54-63.

Nasio, J. D. (1994). El magnífico niño del psicoanálisis. Barcelona: Gedisa.

Volnovich, J. (1999). Los cómplices del silencio. Infancia, subjetividad y prácticas institucionales. Buenos Aires: Lumen/ Hvmanitas.

Winnicott, D. W. (1946). Algunos aspectos psicológicos de la delincuencia juvenil. In Deprivación y delincuencia. Buenos Aires: Paidós, 1998.

\section{NOTAS}

1 Denomina-se "casa de admissāo e avaliação" a instituição que alberga transitoriamente menores sob tutela judicial enquanto é realizada uma avaliação geral da qual o juiz que decide seu "destino" é informado (sic).

2 Roman foi um dos primeiros casos que nos levaram a revisar a denominação de "fuga" entendendo que este é um termo carcerário, e não clínico. Ainda que o tenhamos denominado "ausência sem consentimento", na linguagem cotidiana continuou se falando em "fuga". Como tentamos ilustrar, a leitura destas ausências e os regressos apresentam para nós interesse clínico.

3 Um serviço que existe há muitos anos no municipio de General Pueyrredón, composto por agentes municipais que portam uma carteira de "inspetor de menoridade", denominação que surge da Lei 10067, na qual se outorga aos municípios a autoridade de exercer o poder de policia civil do menor - enquanto auxiliares da Justiça de menores. Ainda que em sua tradição tenha sido um serviço de repressão e de controle da legislação vigente, o 
perfil do inspetor de menoridade foi sendo revisto, aproximando-se da função de operador, excluindo-se explicitamente toda possibilidade de repressão e castigo aos "menores". Um agente municipal, inspetor com muitos anos de experiência, confessou em uma reunião de pessoal: "Antes éramos a carrocinha de crianças, tinhamos que 'levantá-los' e metê-los na Kombi para prendê-los, porque, se não o fizéssemos, nos sancionavam. Hoje as coisas mudaram, e isso é bom. Mas temos que aprender como se faz de outra maneira".

4 Não é à toa que insistimos em modificar os modos de transferência de crianças judicializadas. Esta é realizada por pessoal policial uniformizado como patrulheiro com as conotaçōes de castigo que a policia, o patrulheiro e o policial representam.

5 Lugar onde o Conselho Provincial do Menor centraliza informação e localização de menores em diferentes instituiçōes e/ou programas da Província de Buenos Aires, Argentina.

6 Já a partir desse momento e até nosso contato com ele, começaram as intervençoes de múltiplos profissionais do "sistema de proteção".

7 O ultrapassado regulamento dessas casas proibe expressamente o reingresso quando ocorre uma fuga.

8 Este lugar foi outrora a guarita dos funcionários de uma ferrovia. O municipio acondicionou-o e o reinaugurou com o nome de A Parada das Crianças. A equipe de "amigos" é integrada por profissionais e operadores gestores de uma experiência de tratamento ambulatório destinado a crianças em situaçāo de risco, particularmente meninos em situação de rua.

9 Na giria carcerária, os estupradores (no original: "violadores". N. da T.) são nomeados dessa forma.

10 Apesar de nossa insistência em que pudesse permanecer no hospital por mais tempo a fim de realizar uma avaliação para além do social que nos possibilitasse oferecer um tratamento adequado.

11 E no Código 10 (vagabundagem) (Lei n 10067 do Patronato do Menor) como costuma ocorrer nesses casos. 